\title{
Review Article \\ Experience (Mostly Negative) with the Use of Sympathomimetic Agents for Weight Loss
}

\author{
Mario A. Inchiosa Jr. \\ Departments of Pharmacology and Anesthesiology, New York Medical College, Valhalla, NY 10595, USA \\ Correspondence should be addressed to Mario A. Inchiosa Jr., mario_inchiosa@nymc.edu
}

Received 27 May 2010; Accepted 30 June 2010

Academic Editor: A. Halpern

Copyright (C) 2011 Mario A. Inchiosa Jr. This is an open access article distributed under the Creative Commons Attribution License, which permits unrestricted use, distribution, and reproduction in any medium, provided the original work is properly cited.

Sympathomimetic agents have a poor history of long-term success in the treatment of obesity. From earlier experiences with amphetamine and its analogs, to more recent drugs with direct effects on adrenergic receptors or indirect effects from release of catecholamines or inhibition of reuptake, cardiovascular toxicity (strokes and cardiac arrhythmias) has been the major concern. These concerns also extended to food supplements containing ephedra alkaloids and may require consideration for current supplements containing the sympathomimetic drug, synephrine.

Sibutramine is the most recent drug with sympathomimetic activity that has been recognized by regulatory agencies as having cardiovascular adverse effects that may outweigh its potential value as a weightloss drug. Sibutramine is marketed in Europe under several trade names, including Reductil, Reduxade, Ectiva, Sibutral, Zelium, and others. Meridia is the only brand name in the United States. The European Medicines Agency took definitive action on January 21, 2010 in advising against the continued prescribing of the drug, and Abbott Laboratories suspended sales of the drug in Europe [1]. This action was prompted by a preliminary evaluation of results from the Sibutramine Cardiovascular OUTcome (SCOUT) trial reported by the United States FDA [2]. The FDA has not imposed a ban on the drug but has obtained a change in the boxed warning label to contraindicate its use in patients with a history of cardiovascular disease and in all individuals over 65 years of age (updated warning, April 15, 2010). These regulatory actions were prompted by an early review of the SCOUT trial [3] that revealed an incidence of cardiovascular events of $11.4 \%$ in patients receiving sibutramine compared to $10 \%$ in those receiving placebo. This was an unexpected finding; the hypothesis in the design of the study was that an anticipated weight loss from the use of sibutramine would be associated with a reduction in the incidence of cardiovascular events when compared to that observed in patients receiving the placebo treatment [3].

Sibutramine was not developed as a sympathomimetic drug. In early studies, it was first evaluated for its potential as an antidepressant medication, and its behavioral effects were apparently explained by its inhibition of both 5-hydroxytryptamine (5-HT) and norepinephrine reuptake in the central nervous system (CNS) $[4,5]$. The inhibition of monoamine uptake is produced almost completely by two metabolites of sibutramine [5]. The hypophagic effect of sibutramine was recognized later, and this became the focus of its development as an antiobesity drug [6-8]. Its sympathomimetic effects (an increase in heart rate and blood pressure), which are of concern in relation to the observed increase in adverse cardiovascular events, would appear to be primarily related to a peripheral inhibition of norepinephrine reuptake and interrelationships with sympathetic outflow from the CNS $[9,10]$. The increases in heart rate and blood pressure would be expected to follow from inhibition of norepinephrine reuptake by sibutramine (mostly its metabolites) at sympathetic nerve endings in the heart and blood vessels. This effect would be magnified during physical activity or other conditions of stress that would increase sympathetic nerve activity and norepinephrine overflow in the periphery. These increases 
in heart rate and blood pressure are seen, despite the fact that sibutramine is known to blunt the intensity of central sympathetic outflow by virtue of $\alpha_{2}$-adrenergic suppression of sympathetic activity in the CNS. The locus of this action is considered to include $\alpha_{2}$-adrenergic receptors in the lower portion of the brain stem (medulla oblongata) [11]. This is also the presumed site of action of the antihypertensive drug, clonidine. The extent to which sympathetic outflow is decreased by this central inhibitory effect of overflow norepinephrine may be limited, because sibutramine has been observed to rapidly (within days) desensitize central $\alpha_{2}$ adrenergic receptors in animal studies [12].

Amphetamines, phentermine, and phenyl-propanolamine (PPA) are sympathomimetic amines that were once widely used for the treatment of obesity because of their anorexic effects $[13,14]$. They are all contraindicated for this use at this time because of their adverse cardiovascular and/or behavioral profiles. They are primarily indirect acting amines, that is, they release norepinephrine from sympathetic nerve endings. These amines all have an $\alpha$-methyl substitution, which results in inhibition of monoamine oxidase and an intensification and prolongation of their pharmacological effects. In addition, the dextro isomer of amphetamine, dexamphetamine, is a potent inhibitor of norepinephrine reuptake, which may be the basis for its greater potency over the levoisomer [13]. The unregulated sale of supplements containing ephedra alkaloids is probably the most recent example of the discontinued use of a group of sympathomimetic entities for weight loss. These supplements were banned by the FDA in 2004 because of their unreasonable risks of cardiovascular toxicity. The complete ban on ephedra sales was challenged in 2005; that challenge was overturned on appeal by the FDA, with confirmation of the ban in 2006. The United States Supreme Court declined to review a further industry appeal in 2007. (I have commented previously on the cardiovascular risks of ephedra alkaloids [15].)

As one of several consultants to the FDA before the imposition of the ephedra ban [16], I conducted an evaluation of the pharmacology and inherent safety concerns of ephedra alkaloids. The principal focus in that analysis concerned ephedrine. Although the natural herb, Ephedra sinica (Ma Huang), contains three sympathomimetic agents in addition to ephedrine (pseudoephedrine, methylephedrine, and phenylpropanolamine), ephedrine is the most potent and is typically present in the highest concentration among the four alkaloids [17]. The sympathomimetic impact of ephedrine results from a combination of multiple actions. Ephedrine is classified as both a direct and indirect acting amine. Its indirect effects result primarily from the fact that it causes a displacement release of norepinephrine from sympathetic nerve endings. In addition to releasing norepinephrine, ephedrine blocks the reuptake of norepinephrine into sympathetic nerve terminals. Ephedrine is also an inhibitor of the degradation of norepinephrine by monoamine oxidase. Thus, by three mechanisms, ephedrine magnifies the intensity and duration of action of norepinephrine that is released $[13,14,18]$. Obviously, this entire process is further amplified during periods of physical exercise, where sympathetic nerve activity is increased. In addition to indirect effects of ephedrine, it also has direct vasoconstrictor $\left(\alpha_{1}\right.$-adrenergic), cardiac acceleration and increased contractility ( $\beta_{1}$-adrenergic), and bronchodilator ( $\beta_{2}$-adrenergic) effects. This triad of effects is similar to that of epinephrine. The direct effects of ephedrine summate with its indirect effects to produce its total cardiovascular impact.

A major negative impact of ephedrine upon the heart is its ability to induce cardiac arrhythmias. The primary mechanism involved in this risk is the fact that ephedrine and all sympathomimetic drugs that activate $\beta_{1}$-adrenergic receptors (either directly or through release, inhibition of reuptake, or inhibition of metabolism of norepinephrine) shorten the refractory period of the conducting system of the heart and cardiac muscle [11]. This is particularly problematic in an individual who is exercising, because the increased sympathetic outflow with exercise augments the release of norepinephrine, which itself has $\beta_{1}$-adrenergic activity. This adds to the shortening of refractoriness of cardiac cells. A shortening of the refractory period of myocardial cells is an essential element in the induction of a re-entrant arrhythmia, that is, an impulse may now encounter receptive cells, cells that would ordinarily be refractory and would not allow for a premature activation. That premature activation can permit an abnormal route of electrical excitation, that is, an arrhythmia [19]. In addition, myocardial ischemia caused by exercise and/or exacerbated by the presence of coronary artery obstruction also results in a shortening of the refractory period of myocardial cells $[19,20]$. Since the presence of coronary artery disease may be unrecognized in many individuals during routine activities, the summation of drug and stress effects on the electrophysiology of the heart requires consideration. Recent data presented by the American Heart Association shows that the incidence of cardiovascular disease is 39.6 percent in the age group 40 to 59 years (identical for men and women) and 73.6 percent and 73.1 percent in the age group 60 to 79 years for men and women, respectively [21].

In addition to the risks of stroke associated with blood pressure elevations produced by sympathomimetic drugs, increases in blood pressure may also contribute an arrhythmogenic potential. With increases in blood pressure, compensatory baroreceptor-mediated predominance of the parasympathetic nervous system does result in a slowing of heart rate in comparison to the effect that would take place as a result of $\beta_{1}$-adrenergic activation alone. Although this may reduce the extent of blood pressure elevation, it does not reduce the arrhythmogenic potential of the electrophysiological processes discussed above. In fact, the participation of the parasympathetic nervous system to slow heart rate does so by release of its mediator, acetylcholine. Acetylcholine also shortens the refractory period of atrial tissues, which may be causally related to the induction of atrial fibrillation, atrial flutter, or paroxysmal supraventricular tachycardia [11]. Thus, direct sympathomimetic stimulation of $\beta_{1}$-adrenergic receptors, indirect effects through released norepinephrine, ischemia, and compensatory acetylcholine release, may each be primary or may summate to induce cardiac arrhythmias. 
As a result of the loss of availability of ephedra-containing products, the sympathomimetic amine, synephrine, appears to have become an important focus of the food supplement industry. Synephrine is chemically related to the well-known vasopressor drug, phenylephrine; phenylephrine is the meta-hydroxy-phenyl isomer of synephrine. As with phenylephrine, synephrine increases blood pressure through its $\alpha_{1}$-adrenergic-mediated vasoconstrictor effect [13]. There are a number of supplements currently on the market that identify synephrine as a major ingredient of the product. Information about these products is readily available through searches for synephrine. Various claims are made as to the value of this constituent for weight loss and development of physical fitness. Several of these commercial products contain a fairly well-characterized extract of Citrus aurantium (bitter orange), which is called "ADVANTRA Z". ADVANTRA $Z$ is supplied by Nutratech, Inc. [22]. The descriptions of patents for ADVANTRA $Z$ indicate that, in addition to synephrine, it contains three other orally active sympathomimetic agents, N-methyltyramine, hordenine, and octopamine [13]. The Nutratech website suggests a daily intake of 100 to $120 \mathrm{mg}$ of synephrine, in two to three divided servings.

The potential cardiovascular effects of the doses of synephrine present in ADVANTRA $Z$ can be placed in perspective because synephrine is the active ingredient in the orally active vasopressor drug, oxedrine tartrate. A common trade name for this preparation in Europe is Sympatol [23]. Oxedrine tartrate is not marketed in the United States. Sympatol carries the clinical indication for the treatment of hypotension, that is, to raise blood pressure, with oral doses of 100 to $150 \mathrm{mg}$, up to three times a day. To compare doses of synephrine in ADVANTRA $Z$ with clinical doses of Sympatol, it is necessary to correct for the fact that Sympatol is the racemic mixture of synephrine (the $l$-isomer has the predominant sympathomimetic activity) and that it is the tartrate salt. (The $l$-isomer of synephrine is the form in citrus extracts $[24,25]$.) Therefore, the molecular weight of synephrine tartrate is 484.5 . Of this, the $l$-synephrine content is 167.2 or $34.5 \%$ of the dose.

Thus, the single oral dose range of 100 to $150 \mathrm{mg}$ of Sympatol supplies 34.5 to $51.8 \mathrm{mg}$ of $l$-synephrine. If 3 doses are given per day, the total daily dose would be 103.5 to $155.4 \mathrm{mg}$ of synephrine. This overlaps the suggested intake for ADVANTRA Z of 100 to $120 \mathrm{mg}$ of synephrine per day. As discussed above, in addition to the danger of stroke associated with drug-induced increases in blood pressure, compensatory responses to these increases, mediated through the parasympathetic nervous system, may be arrhythmogenic. Also, these concerns would be expected to be enhanced in conjunction with physical effort. The National Center for Complementary and Alternative Medicine, National Institutes of Health, has noted the potential risks for cardiovascular toxicity from consumption of extracts of Citrus aurantium [26].

In summary, sympathomimetic agents do not have a successful record for the treatment of weight loss. They apparently possess an unreasonable cardiovascular toxic potential that emerges when the drugs are applied to a broad spectrum of the population, many of whom may have unrecognized risk factors.

\section{Disclosure}

The author was compensated as a consultant to the US Food Administration for evaluation of sympathomimetic agents in food supplements.

\section{References}

[1] European Medicines Agency, "European Medicines Agency recommends suspension of marketing author-isations for sibutramine," January 2010, http://www.ema.europa.eu/pdfs/ human/referral/sibutramine/3940810en.pdf.

[2] "Follow-up to the November 2009 early communication about an ongoing safety review of sibutramine," Department of Health and Human Services, U.S. Food and Drug Administration, Meridia, January 2010, http://www.fda.gov/ Drugs/ DrugSafety / PostmarketDrugSafetyInformationforPatientsandProviders/DrugSafetyInformationforHeathcareProfessionals/ucm 198206.htm.

[3] "Early communication about an ongoing safety review of Meridia (sibutramine hydrochloride)," Department of Health and Human Services, U.S. Food and Drug Administration, November 2009, http://www.fda.gov/Drugs/ DrugSafety/PostmarketDrugSafetyInformationforPatientsandProviders/DrugSafetyInformationforHeathcareProfessionals/ ucm191650.htm.

[4] W. R. Buckett, P. C. Thomas, and G. P. Luscombe, "The pharmacology of sibutramine hydrochloride (BTS 54 524), a new antidepressant which induces rapid noradrenergic down-regulation," Progress in Neuro-Psychopharmacology and Biological Psychiatry, vol. 12, no. 5, pp. 575-584, 1988.

[5] G. P. Luscombe, R. H. Hopcroft, P. C. Thomas, and W. R. Buckett, "The contribution of metabolites to the rapid and potent down-regulation of rat cortical $\beta$-adrenoceptors by the putative antidepressant sibutramine hydrochloride," Neuropharmacology, vol. 28, no. 2, pp. 129-134, 1989.

[6] M. Fantino and A.-M. Souquet, "Effects of metabolites 1 and 2 of sibutramine on the short-term control of food intake in the rat," International Journal of Obesity, vol. 19, article 145, 1995.

[7] J. C. G. Halford, D. J. Heal, and J. E. Blundell, "Effects in the rat of sibutramine on food intake and the behavioral satiety sequence," British Journal of Pharmacology, vol. 114, p. 387P, 1995.

[8] H. C. Jackson, M. C. Bearham, L. J. Hutchins, S. E. Mazurkiewicz, A. M. Needham, and D. J. Heal, "Investigation of the mechanisms underlying the hypophagic effects of the 5HT and noradrenaline reuptake inhibitor, sibutramine, in the rat," British Journal of Pharmacology, vol. 121, no. 8, pp. 16131618, 1997.

[9] A. L. Birkenfeld, C. Schroeder, M. Boschmann et al., "Paradoxical effect of sibutramine on autonomic cardiovascular regulation," Circulation, vol. 106, no. 19, pp. 2459-2465, 2002.

[10] K. Heusser, S. Engeli, J. Tank et al., "Sympathetic vasomotor tone determines blood pressure response to long-term sibutramine treatment," Journal of Clinical Endocrinology and Metabolism, vol. 92, no. 4, pp. 1560-1563, 2007. 
[11] T. C. Westfall and D. P. Westfall, "Adrenergic agonists and antagonists," in Goodman \& Gilman's the Pharmacological Basis of Therapeutics, L. L. Brunton, J. S. Lazo, and K. L. Parker, Eds., pp. 237-295, McGraw-Hill, New York, NY, USA, 11th edition, 2006.

[12] D. J. Heal, M. R. Prow, J. Gosden, G. P. Luscombe, and W. R. Buckett, "A comparison of various antidepressant drugs demonstrates rapid desensitization of $\alpha_{2}$-adrenoceptors exclusively by sibutramine hydrochloride," Psychopharmacology, vol. 107, no. 4, pp. 497-502, 1992.

[13] "Peripheral adrenergic mechanisms," in Textbook of Pharmacology, W. C. Bowman and M. J. Rand, Eds., pp. 11.1-11.49, Blackwell Scientific, Oxford, UK, 2nd edition, 1980.

[14] "The diet and diet-induced diseases. Appetite control. Pharmacologically active constituents of food," in Textbook of Pharmacology, W. C. Bowman and M. J. Rand, Eds., pp. 43.1-43.51, Blackwell Scientific, Oxford, UK, 2nd edition, 1980.

[15] M. A. Inchiosa Jr., "Concerning ephedra alkaloids for weight loss," International Journal of Obesity, vol. 31, no. 9, p. 1481, 2007.

[16] M. A. Inchiosa Jr., "Reports from Outside Consultants," Department of Health and Human Services, U.S. Food and Drug Administration. Federal Register Notice-65 FR 17510, April 2000-Dietary Supplements Containing Ephedrine Alkaloids, http://www.fda.gov/Food/DietarySupplements/GuidanceComplianceRegulatoryInformation/RegulationsLaws/ ucm079601.htm Document ID: FDA-2000-N-0284-0019.8, http://www.regulations.gov/search/Regs/home.html\#dodocumentDetail?R=0900006480934c08.

[17] L. M. White, S. F. Gardner, B. J. Gurley, M. A. Marx, P.-L. Wang, and M. Estes, "Pharmacokinetics and cardiovascular effects of Ma-Huang (Ephedra sinica) in normotensive adults," Journal of Clinical Pharmacology, vol. 37, no. 2, pp. 116-122, 1997.

[18] "Noradrenergic transmission," in Pharmacology, H. P. Rang, M. M. Dale, J. M. Ritter, and P. Gardner, Eds., pp. 139163, Churchill Livingstone, New York, NY, USA, 4th edition, 2001.

[19] D. M. Roden, "Antiarrhythmic drugs," in Goodman \& Gilman's the Pharmacological Basis of Therapeutics, L. L. Brunton, J. S. Lazo, and K. L. Parker, Eds., pp. 899-932, McGraw-Hill, New York, NY, USA, 11th edition, 2006.

[20] "The heart and drugs affecting cardiac function," in Textbook of Pharmacology, W. C. Bowman and M. J. Rand, Eds., pp. 22.1-22.85, Blackwell Scientific, Oxford, UK, 2nd edition, 1980.

[21] American Heart Association, "Heart disease and stroke statistics-2010 update. (Slide 10)," http://www.americanheart .org/downloadable/heart/12626426574432010\%20Stat $\% 20$ charts\%20FINAL.ppt\#343,10,Slide 10.

[22] Nutratech Inc., "Advantra $Z^{\circledR}$. The next generation weight loss \& fitness ingredient. Applications/dosage guidelines," http:// www.nutratechinc.com/advz/advz.php? $\mathrm{p}=4$.

[23] S. C. Sweetman, Ed., Martindale the Complete Drug Reference, Pharmaceutical Press, London, UK, 36th edition, 2009.

[24] I. Stewart, W. F. Newhall, and G. J. Edwards, "The isolation and identification of $l$-synephrine in the leaves and fruit of citrus," Journal of Biological Chemistry, vol. 239, pp. 930-932, 1964.
[25] F. Kusu, K. Matsumoto, K. Arai, and K. Takamura, "Determination of synephrine enantiomers in food and conjugated synephrine in urine by high-performance liquid chromatography with electrochemical detection," Analytical Biochemistry, vol. 235, no. 2, pp. 191-194, 1996.

[26] National Institutes of Health, National Center for Complementary and Alternative Medicine. Bitter Orange, http://nccam.nih.gov/health/bitterorange/\#cautions. 


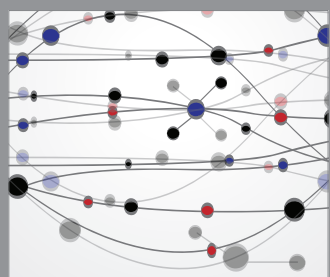

The Scientific World Journal
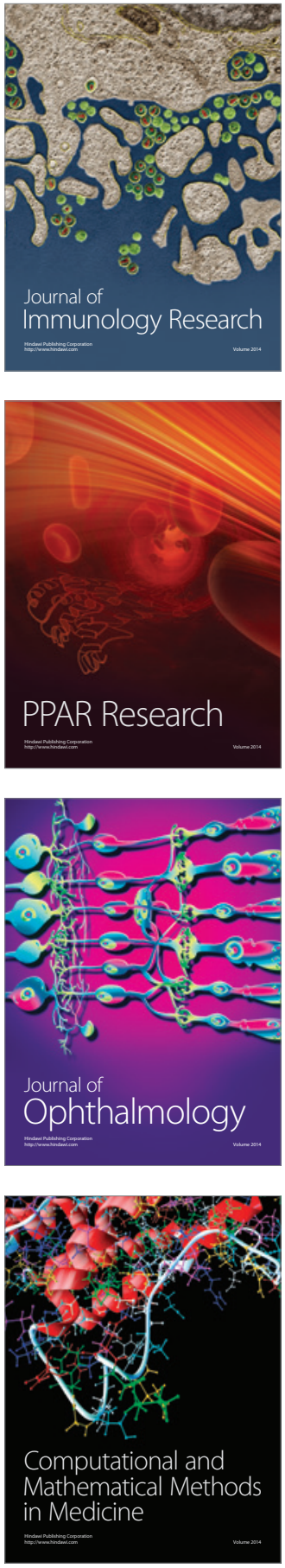

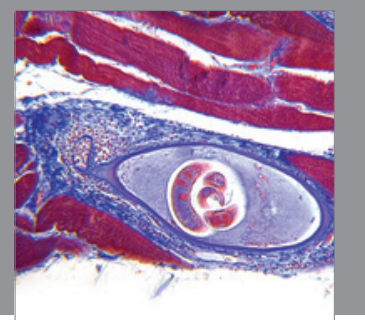

Gastroenterology

Research and Practice
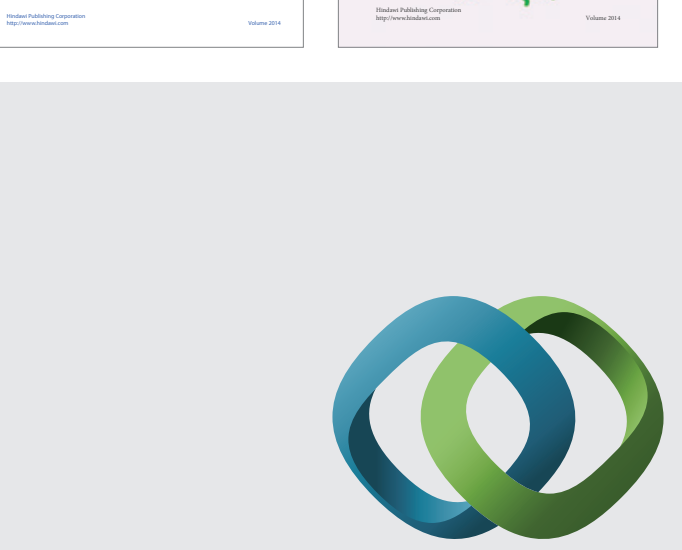

\section{Hindawi}

Submit your manuscripts at

http://www.hindawi.com
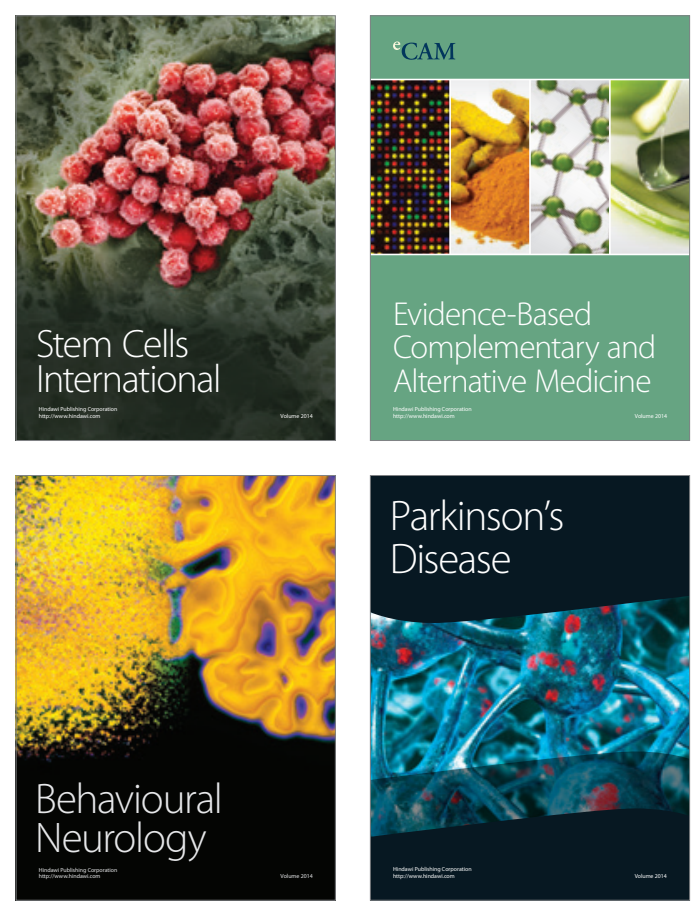

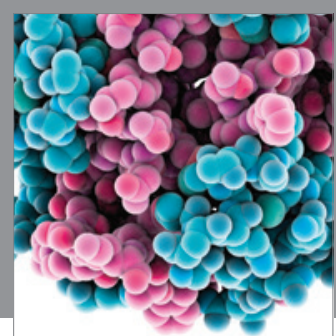

Journal of
Diabetes Research

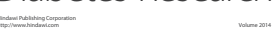

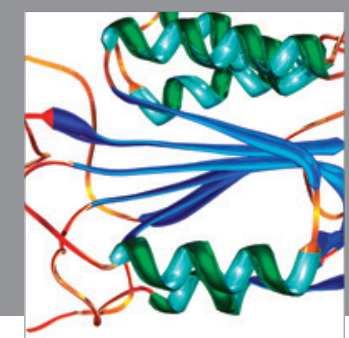

Disease Markers
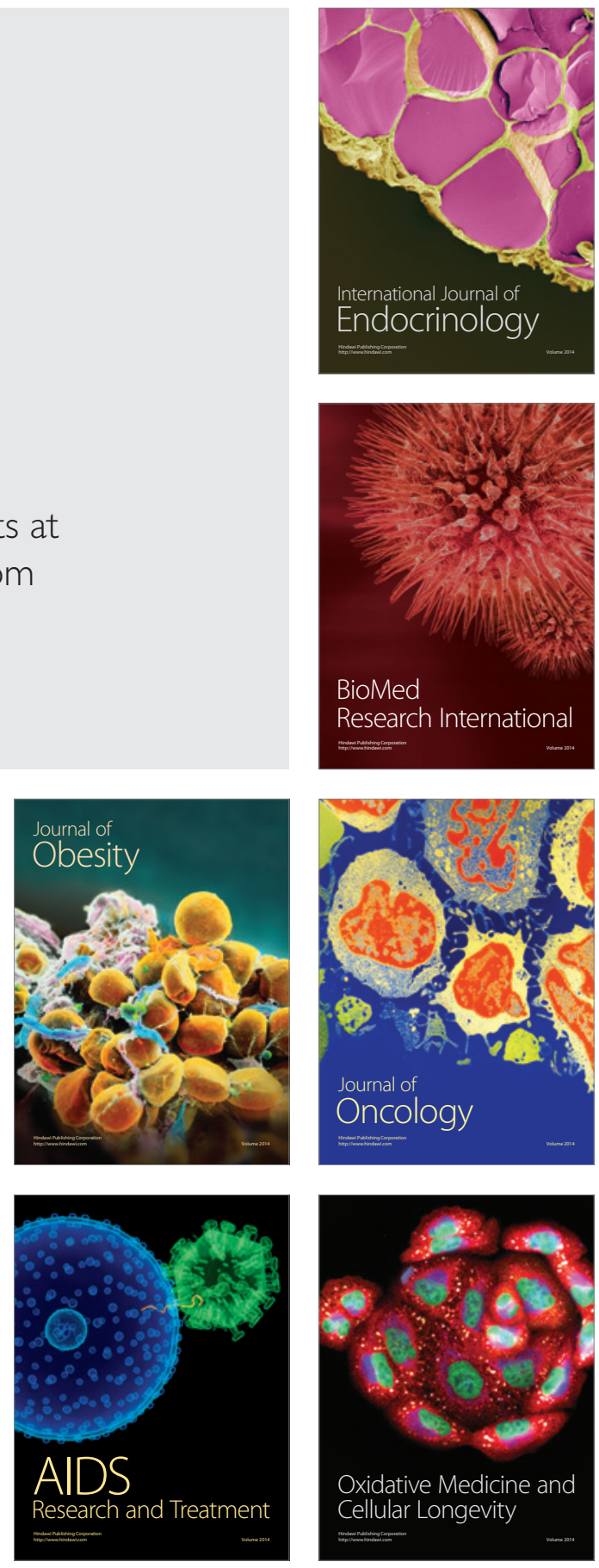